\title{
Work, rehabilitation and mental health
}

\section{Sinead McGilloway, Michael Donnelly}

To cite this article: Sinead McGilloway, Michael Donnelly (2000) Work, rehabilitation and mental health, Journal of Mental Health, 9:2, 199-210, DOI: 10.1080/09638230050009195

To link to this article: https://doi.org/10.1080/09638230050009195

$$
\text { 曲 Published online: 06 Jul } 2009 .
$$

Submit your article to this journal 정

\section{Article views: 85}

Q View related articles $\sqsubset$

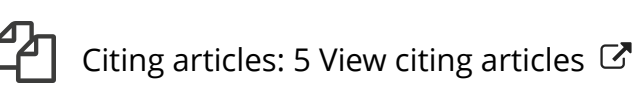




\title{
Work, rehabilitation and mental health
}

\author{
SINÉAD MCGILLOWAY ${ }^{1} \&$ MICHAEL DONNELLY ${ }^{2}$
}

${ }^{1}$ Department of Psychology, National University of Ireland, Maynooth, Ireland \& ${ }^{2}$ Health and Social Care Research Unit, Queen's University Belfast, Belfast, Northern Ireland, UK

\begin{abstract}
This study was undertaken to evaluate a new employment initiative called ACCEPT - Assessment Counselling and Coaching in Employment Placement and Training for people with mental health problems. Pre- (T1) and post-training (T2) assessments of 63 ACCEPT trainees - based on the Lancashire Quality of Life Profile - indicated statistically significant improvements $(p<0.05)$ at T2 in satisfaction with employment status, religion and purpose in life, social relationships and overall wellbeing as well as a statistically significant increase in overall self-esteem scores. Minor psychiatric morbidity (GHQ) also decreased significantly $(p<0.05)$ after training. Trainees' own views about ACCEPT were positive. At the end of the study, approximately half (32/63) were in paid employment or in part/full-time voluntary work or work experience. Mental health professionals $(n=52)$ were generally in favour of the service, although some expressed concern about staffing, client placements and inter-agency communication. The findings highlight, among other things, the importance of 'therapeutic outcomes' and the critical role of effective inter-agency working and support from mental health professionals in the success of work-orientated programmes of care.
\end{abstract}

\section{Introduction}

The social and psychological significance of work or work-related activity and, in turn, the negative impact of unemployment on mental health are well documented (e.g. Warr, 1984). People with psychiatric problems, more than any other client group, require guidance and support to secure and maintain employment or to return to work after a period of mental ill health. Traditionally, opportunities for people with mental ill health to re-enter open employment have been limited owing to, among other things, the social stigma associated with their illness and the lack of dedicated vocational rehabilita- tion/training services. However, a relatively rapid expansion in these services during the last decade has led to the implementation of a wide range of statutory and voluntary schemes and facilities which address the employment needs of people with mental ill health. These include: hospital-based programmes; sheltered work; assertive casemanagement; psychosocial rehabilitation including prevocational training, transitional employment and volunteer placements; supported employment; and counselling and education (Bond \& Boyer, 1988).

The growth in employment and training provision for mentally ill people reflects an increasing need to address the dynamic inte- 
raction between individuals and their social environment particularly against a background of hospital closures and resettlement to the community (Shepherd, 1997). Increasing numbers of people with psychiatric disorder require, in addition to clinical management and medication regimens in the community, a network of innovative daytime services which extend beyond traditional (and largely stigmatised) provision and which help to address the secondary and tertiary disabilities described by Wing (1981) in his 'disability' model of rehabilitation. Bachrach (1992) states that psychiatrists, in particular, play a critical role in addressing the secondary disabilities of people with mental illness (i.e. how they understand and deal with their illness) and that this can be achieved most effectively with the help of rehabilitative interventions involving skills training, behavioural change and environmental adaptation. Available evidence supports the view, also promulgated by Bachrach (1992), that psychiatry and vocational rehabilitation complement each other in the extent to which they contribute to patients' welfare and life circumstances.

The importance of employment support has been recognised in the US for some time now, but there is a growing number of organisations in the UK which promote actively employment-orientated programmes as part of their core provision (Grove, 1999). Among the key players in Northern Ireland is New Horizons (formerly known as the Industrial Therapy Organisation) which organises and administers the ACCEPT service.

\section{The ACCEPT service}

ACCEPT is a relatively new service which was implemented within the EmploymentHorizon initiative of the European Union. According to the above classification, it may be described as a psychosocial rehabilitation service involving the Assessment Counselling and Coaching in Employment Placement and Training for people whose employability has been, or is likely to be, affected by mental illness. The ACCEPT initiative in Northern Ireland (ACCEPT (NI)) was set up in November 1995 and currently involves a collaboration with over 200 different agencies in 11 other countries including England, Germany, Spain, Sweden and Greece. ACCEPT (NI) comprises 17 statutory and voluntary organisations including several Health and Social Services (HSS) Trusts. This 'flagship' model of multi-agency working developed within a region of the UK often considered more strongly associated with division and civil unrest than partnership. Most ACCEPT (NI) activity revolves around four 'high street' information centres in Belfast and surrounding areas. Each centre which is staffed by a Development Officer (DO), administrator and, on occasion, one or more volunteers - provides a range of activities including: general advice and information to service-users, carers and mental health professionals; one-to-one guidance and job counselling; in-house training; help to gain a place in Further Education; and work placement/employment with ongoing monitoring and support. Over 3000 people received one or more of the above during 1997 (e.g. 386 people received vocational training). Training courses include: Personal Development Skills (e.g. confidence-building course); Preparation for Job-Skills; Introduction to Computers; Computer Literacy and Information Technology (CLAIT); Stress Management; and Work and Coping Skills.

This study was undertaken to evaluate the services provided by the four ACCEPT centres during their first 12-18 months of operation. Its aims were to: (1) obtain a profile of ACCEPT service-users; (2) determine -in so far as possible within the relatively short 
time-scale of the study - the extent to which people obtained employment or meaningful occupation after attending ACCEPT; (3) assess by means of a face-to-face survey the extent to which ACCEPT (NI) had met the needs of a sample of users and impacted on their quality of life, mental health and general functioning; and (4) undertakea 'stakeholder' survey to elicit the views of mental health professionals and mental health service managers in contact with ACCEPT.

\section{Method}

All those who enrolled for one or more ACCEPT training course(s) during the study period (August-November 1997) and who agreed to participate in the research were assessed before and after completion of training. Those receiving ACCEPT information and guidance only were excluded from the study. Pre-training (T1) assessments and interviews were conducted with 74 people but $11(15 \%)$ dropped out shortly afterwards. Complete T1 and T2 (post-training) data were available, therefore, for 63 people. However, two of those who dropped out later agreed to complete some of the self-report questionnaires used in the study. Each trainee was assessed using the instruments described below.

A profile of trainees was obtained using an ACCEPT Intake Form (AIF) to record: sociodemographic information; primary diagnosis; current medication; experience of 'institutional' environments; employment history and qualifications; and subjective wellbeing and coping.

The Lancashire Quality of Life Profile (LQOLP) (Oliver et al., 1995) was used to elicit information on perceived quality of life. It includes Life Satisfaction Scores (LSS) or ratings in eight major life domains (including health and general wellbeing and social relationships) as well as Bradburn's (1969) Affect Balance Scale - a 10-item measure of psychological wellbeing - and Rosenberg's 10-item self-esteem schedule (Rosenberg, 1965). The GHQ-12(Goldberg, 1978 ) provided a measure of minor psychiatric morbidity while the four-item CAGE (Ewing \& Rouse, 1970) was employed as an alcohol screening instrument.

A GoalAttainment Form $(G A F)$-based on work by Kiresuk \& Sherman (1968) - recorded information on up to five goals or objectives (listed in order of importance) which the trainee hoped to achieve as a result of attending ACCEPT and the extent to which these had been met on completion of training (e.g. rated by both staff and trainee on a scale from 1 ('much more than expected') to 5 ('much less than expected')).

Respondents' views about ACCEPT (e.g. ratings of service quality) were elicited using an eight-item Client Evaluation Form (CEF). A 21-item Stakeholder Questionnaire (SQ) was employed in the postal survey of professionals in contact with ACCEPT. The SQ includes questions relating to the perceived contribution of ACCEPT services to the trainee's wellbeing, the positive and negative aspects of the service and how the service might be improved. Additional semi-structured interviews were conducted with key informants representing each of the HSS trusts with a 'stake' in the four ACCEPT centres.

\section{Results}

\section{Profile of trainees}

More than half $(53 \%)$ of the trainees were female and most were in their late thirties and living with their family (Table 1). There were no statistically significant differences $(p>0.05)$ in marital status or living circumstances with respect to age or sex. Fifty-three 
per cent (39/74) were referred formally to ACCEPT usually by a Community Psychiatric Nurse (CPN) or social worker (26/39). The remainder were 'self-referrals'. Fiftynine per cent of the group - particularly those in the older age group (45-58 years) $\left(\chi^{2}=\right.$ $7.15, \mathrm{df}=2, p<0.05)$ - had a non-psychotic illness. There was no statistically significant association $(p>0.05)$ between diagnosis and sex. Fifty-nine people $(80 \%)$ were taking mainly antidepressant or antipsychotic medication. Almost half $(47 \%, 35 / 74)$ of the group had spent 10 weeks on average in psychiatric in-patient care; $24 \%$ (18/74) were admitted during the previous year (Table 1).

The majority of trainees $(70 \%, 52 / 74)$ were receiving one or more mental health service(s) (Table 1) usually provided by a CPN $(60 \%$, $21 / 35)$, psychiatrist $(54 \%, 19 / 35)$ or social worker $(43 \%, 15 / 35)$. Eight people were seeing a counsellor/psychotherapist (5) or psychologist (3) while three people were attending a day hospital. Five trainees, three of whom had a psychotic illness, had never

Table 1: Profile of trainees (at intake)

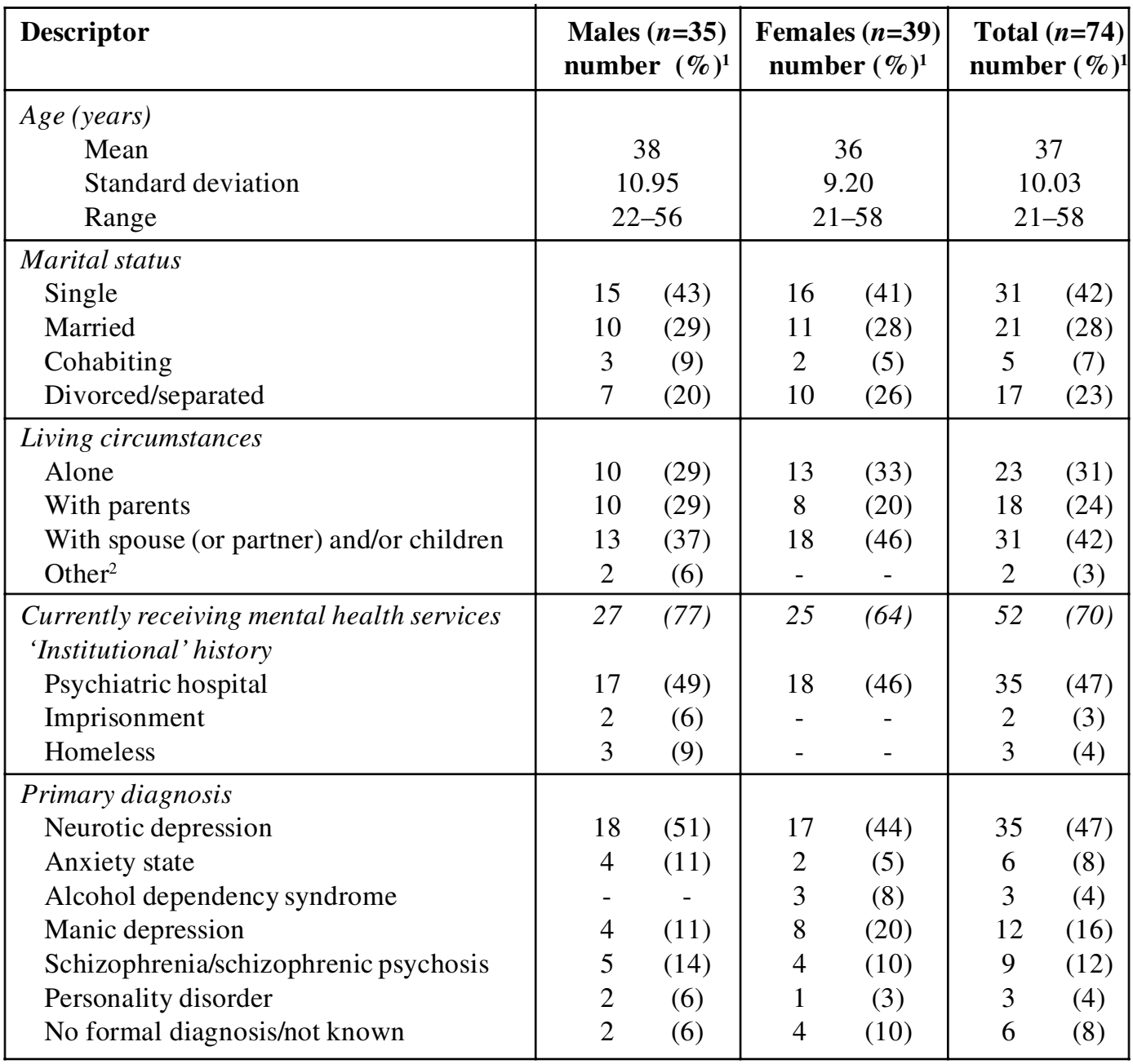

${ }^{1}$. Percentages may not sum to 100 due to rounding,

2. 'Other' includes two people who were living with their brother and friend, respectively. 
been in full-time employment, but half had spent 10 or more years in working life, usually in non-manual or manual-skilled employment. Almost two-thirds were currently unemployed for more than a year $(65 \%, 48 /$ $74)$. Almost half $(46 \%, 34 / 74)$ the group had left school at 16 although $72 \%(53 / 74)$ had one or more qualification(s). Mental ill health was the most commonly cited reason $(62 \%$, 42/74) for unemployment. Almost two-thirds of trainees were rated by ACCEPT staff as ha-ving average $(34 \%, 25 / 74)$ or high $(28 \%$, $21 / 74)$ levels of wellbeing and coping ability.

\section{Profile of 'leavers'}

Six of the 11 people who dropped out of training were 'self-referrals', all but two were female and most were in their mid- to late thirties (mean $=35$ years). Two had received psychiatric in-patient care (4-6 weeks), six were taking medication and four were in contact with mental health service professionals including a CPN (2), social worker (2) and psychiatrist (1). All but two had a non-psychotic illness. The 'leavers' were similar in all other respects to those who completed their training. Only two people replied to a follow-up letter, one of whom indicated that she had gone on to further education; the second respondent left ACCEPT because he was seeking a joinery apprenticeship.

At the end of the study, one third (21/63) of trainees were involved in part- or full-time voluntary work or work experience while nine people $(14 \%)$ were in sheltered work. Almost one in five $(17 \%, 11 / 63)$ were in paid employment and a further two people were attending further education classes. The remainder $(27 \%, 17 / 63)$ - excluding five people with whom ACCEPT staff were no longer in contact - had enrolled for further ACCEPT training courses.

\section{Face-to-face survey}

$T$-tests were used to examine pre- and posttraining differences in the mean LSS scores (the normality of the distribution of scores was checked using $P$-P probability plots). People felt significantly more satisfied $(p<0.05)$ at T2 with: the way they were coping with unemployment; their religion and purpose in life; social relationships; and their lives overall (Table 2). There was a statistically significant increase in overall self-esteem $(p<0.05)$ coupled with significantly lower levels $(p<0.05)$ of psychological distress as measured on the GHQ-12. Forty per cent of the group (26/63) scored below the clinical threshold on the GHQ-12 at both time points. However, 54\% (18/33) of 'cases' at T1 had become 'non-cases' by T2 compared to only $9 \%$ (6/63) for whom the reverse was true. There was no statistically significant association ( $p>0.05)$ between 'caseness' and either sex or diagnostic group (i.e. psychotic versus non-psychotic). Seven people (11\%) scored two or more on the CAGE indicating potential alcohol depen-dency.

The principal pre-training goal identified by trainees was confidence-building, although beginning or returning to full or part-time work was also mentioned, albeit as a less important (e.g. third or fourth) goal. At least three-quarters of trainees had - according to their own ratings and those provided by staff - achieved their goal(s) as much if not more than expected particularly the first and most important goal. The reasons why, according to staff, clients did not reach their expected level of goal attainment included 'lack of commitment or motivation' $(n=15)$, 'unexpected changes in personal circumstances' $(n=7)$ and/or 'deterioration in physical or mental health' $(n=6)$. Other factors included 'lack of suitable jobs' ( $n=6)$, insufficient time and/or training $(n=5)$ and 'inadequate travel arrangements' $(n=3)$. 
Table 2: LQOLP Life Satisfaction and global wellbeing scores $(n=63)$

\begin{tabular}{|l|c|c|c|c|c|c|}
\hline Dimension & $\begin{array}{c}\text { Mean score* } \\
\text { at T1 }\end{array}$ & SD & $\begin{array}{c}\text { Mean score* } \\
\text { at T2 }\end{array}$ & SD & $\boldsymbol{t}$ value & $\begin{array}{c}\text { Significance } \\
\text { level }\end{array}$ \\
\hline Being unemployed $^{1}$ & 3.13 & 2.04 & 3.61 & 2.28 & -2.34 & $p<0.05$ \\
Finance $^{2}$ & 6.35 & 2.99 & 6.49 & 3.21 & -0.42 & $N S$ \\
Living situation $^{3}$ & 13.83 & 3.51 & 13.48 & 3.33 & 1.06 & $N S$ \\
Leisure $^{2}$ & 13.03 & 2.88 & 12.79 & 3.20 & 0.56 & $N S$ \\
Religion $^{2,6}$ & 9.06 & 2.25 & 9.52 & 2.15 & 0.65 & $p<0.05$ \\
Health $^{3}$ & 12.30 & 3.41 & 12.51 & 3.40 & -0.52 & $N S$ \\
Legal and safety $^{2}$ & 10.03 & 2.40 & 9.92 & 2.47 & 0.39 & $N S$ \\
Family relations $^{3}$ & 9.73 & 3.52 & 10.06 & 3.59 & -1.03 & $N S$ \\
Social relations $^{2}$ & 8.73 & 2.57 & 9.24 & 2.37 & -2.05 & $p<0.05$ \\
Life as a whole $^{1}$ & 3.51 & 1.48 & 3.84 & 1.37 & -2.02 & $p<0.05$ \\
Affect $^{4}$ & -1.59 & 4.69 & -1.24 & 5.07 & -0.57 & $N S$ \\
Overall self-esteem $^{4}$ & -0.64 & 4.92 & 0.60 & 5.25 & -2.29 & $p<0.05$ \\
GHQ-12 $^{5}$ & 4.23 & 4.30 & 2.82 & 3.96 & 2.29 & $p<0.05$ \\
\hline
\end{tabular}

*Higher scores - with the exception of the GHQ-12 - mean better outcomes on all dimensions.

${ }^{1}$ Maximum possible score $=7$.

2. Maximum possible score $=14$

${ }^{3}$ Maximum possible score $=21$

4. Possible scores range from -5 to +5

5. Possible scores range from 0 to 12

${ }^{6}$.Scores were obtained for only 27 people who described themselves as 'religious'

Trainees' views about ACCEPT were extremely positive. They mentioned, in particular, improvements in their self-esteem, confidence and motivation, the encouragement and support which they derived from ACCEPT staff and the opportunity for greater social interaction. However, some trainees felt that they needed more and/or longer periods of training and/or more counselling/ one-to-one support and help to find employment.

\section{Stakeholder survey}

Fifty-two questionnaires (52\%) were returned by professionals in contact with the ACCEPT service, most of whom included CPNs $(31 \%, 16 / 52)$, social workers $(19 \%$, 10/52) and occupational therapists (OTs) $(13 \%, 7 / 52)$. Professional estimates of the proportion of clients on caseload considered suitable for referral to ACCEPT varied from $10 \%$ to more than $50 \%$. Most respondents $(71 \%, 37 / 52)$ felt that ACCEPT services had made a positive contribution to their clients' wellbeing, particularly in relation to confidence-building and preparation for work.

These views were amplified in semi-structured interviews with three mental health service managers and two CMHT leaders. ACCEPT was viewed by these key informants as a more flexible, smaller-scale and accessible alternative to training/daytime services such as job clinics (which tend to focus on a different, usually more chronic client group). Participants also mentioned: the accessibility of the information centres as well as their pleasant and de-stigmatising exterior and interior; the time and effort af- 
forded individual clients; the contribution of the service to client empowerment and inclusion; its cross-community benefits in bringing together people from different religious backgrounds; the European dimension (seen, for example, as an important and influential backdrop to the initiative); and the leading role of the voluntary sector in the local ACCEPT initiative. However, all 'stakeholders' expressed concerns about staffing levels, the availability of work placements and the need for greater inter-agency communication, most notably between ACCEPT and the Community Mental Health Team.

\section{Discussion}

Despite recent work by authors in the UK and elsewhere (e.g. Becker \& Drake, 1994; Pozner et al., 1996; Schneider, 1998), there is a continuing need for research on the benefits or otherwise of vocational rehabilitation/training services for people with a mental illness. This study - which represents the first research evaluation of an ACCEPT initiative in Europe - was designed to assess the extent to which the ACCEPT (NI) model of vocational training provides an appropriate, effective and valued service for people with mental ill health. The study focuses on the therapeutic outcomes of vocational rehabilitation/training (e.g. subjective quality of life) which have, for the most part, been neglected by mainstream research and practice (Lehman, 1995).

\section{The service-users}

Our findings are based on a group of consecutive attenders who were considered representative of ACCEPT users. The results suggest, in line with the few studies conducted elsewhere (e.g. McCrohan etal., 1994), that vocational rehabilitation trainees tend to be diverse in terms of their overall function- ing, capabilities, aspirations and employment histories. The ACCEPT trainees were dissimilar, in some respects, to the 77 local job clinic attenders studied by McCrum et al. (1997). For example, more of the people in our study were females, living alone, shorterterm unemployed ( $<5$ years) and less likely to be in need of psychiatric in-patient care. Evidence from elsewhere suggests that users of traditional day care services (e.g. day centres and sheltered workshops) tend to be predominantly middle-aged men with schizophrenia (e.g. Wainwright et al., 1988; Drake et al., 1994; Dick \& Shepherd, 1994). Although no information on severity of illness was available here, our findings suggest that local job clinics and conventional services may be catering for more chronically ill clients than those attending ACCEPT. None the less, a significant majority of trainees were using mental health services while almost half had, at some stage, been hospitalised. The hospital admission rate during the previous year (24\%) compares favourably to that reported by Schneider and Hallam (1997) $(18 \%)$ in their study of a similar vocational rehabilitation scheme in England and is much lower than the $42 \%$ of clients surveyed by Oliver et al. (1995) in their survey of the client caseload of Lancashire Social Services Department.

Significantly, half of the group had spent 10 or more years in working life. Therefore, they may have a good chance of gaining successful long-term placements and/or paid employment in view of evidence suggesting past work history to be the best predictor of future work performance (Anthony \& Jansen, 1984; Bond \& Boyer, 1988). The goals identified by trainees tended to reflect a pattern of increasing aspirations towards paid employment. For example, gaining employment was only the third most commonly cited reason (42\%) for attending ACCEPT. 
This suggests that most people had, at least in the short term, an awareness of their lack of appropriate skills/career direction and/or confidence to re-enter the job market. This is also reflected in the high proportion of trainees for whom gaining confidence was the most important goal.

The findings reported here tend to support the view that a person with a mental health problem may start a vocational training program with a desire to work, but may not actively seek employment until much later when sufficient cognitive and behavioural change has taken place to make the transition from being unemployed and not actively seeking work to being unemployed and searching for a job (Kaufman, 1995). The process of securing employment may develop over time - influenced not only by clients' needs, abilities and aspirations, but also 'external' factors such as a relapse or deterioration in their illness. The follow-up information on the current employment situation of ACCEPT trainees - obtained approximately 6 months after data collection began - appears promising in terms of the number of people in competitive employment and work placements (including voluntary work) and the level of follow-up contact with clients.

Our results suggest that there may be merit in some aspects of the 'train and place' model on which ACCEPT is based as well as the IPS (Individual Placement and Support) 'place and train' programme advocated by Becker and colleagues (Becker \& Drake, 1994; Bond et al., 1997). It is worth noting, however, that there are some similarities between the local ACCEPT model and the American IPS programme. For example, ACCEPT strives increasingly to incorporate 'real work experience' into its programme (four Employment Placement Officers have been appointed since the completion of the study) and it is based on the, often neglected, preferences and choices of clients rather than provider judgements, the importance of which have also been highlighted in this study. However, it is difficult to draw meaningful comparisons between the ACCEPT and IPS models because the vocational outcomes (e.g. job acquisition) and costs associated with supported employment programmes in the US may vary considerably from those in the UK owing to the radically different social security and health insurance systems (Schneider, 1998). In addition, few of the American (or UK) studies focus on the quality of life of the individual subsequent to participation in employment programmes (Schneider, 1998).

A substantial proportion of people in this study was not formally referred to ACCEPT by mental health professionals despite the relatively large number who were receiving their services. It is difficult, on the basis of this study, to ascertain to what extent this pattern of referral was influenced by professional attitudes and/or client need. However, some of our qualitative data suggest that there were teething difficulties with respect to the development of understanding and cooperation between the CMHT and ACCEPT staff. This appeared less to do with the content, delivery and perceived effectiveness of the service than its guiding philosophy which is based mainly on the 'skills' model of rehabilitation (Anthony \& Liberman, 1986) rather than the medical/curative or needsbased approaches (e.g. Wing, 1981; Pilling, 1991) more commonly favoured by mental health professionals. The more broadly defined skills approach is based on a systematic identification of a person's skills and skills deficits in the context of his/her environment and social role with a view to developing greater competency and a clear direction for work. Unlike other models of rehabilitation, it places little or no emphasis on the person's illness and its treatment or its potentially 
unstable effects (Ekdawi \& Conning, 1994).

Our findings concur with previous work suggesting that inter-agency communication difficulties and conflicts are common when vocational services are provided by an 'outside' service and that inter- and intra-agency co-ordination must be an important part of vocational intervention planning in order that resources can be used most effectively (Becker \& Drake, 1994; McCrohan et al., 1994). These and other concerns about staffing and placement availability reflect, in large part, the evolving nature of the service. However, it is important to note that, overall, mental health professionals are in favour of ACCEPT which they consider to be important for people with mental illness and as good, if not better, than alternative employment and daytime services.

\section{Therapeutic outcomes}

Our findings illustrate the critical role of meaningful work-related activity in the extent to which it provides a valued social position as well as a strong sense of identity and self-worth for people with typically low levels of confidence or little intrinsic belief in their value to society (Jahoda, 1981; Lam \& Power, 1991). A small number of studies conducted elsewhere have reported similar results. For example, Velasquez \& McCubbin (1980) reported that those receiving vocational rehabilitation had higher scores than non-attenders on social participation and selfconcept. In addition, Arns \& Linney (1993) observed that a change in vocational status impacted on both self-esteem and ove-rall quality of life. The reduction in minor psychiatric morbidity as measured by the GHQ12 is consistent with reports on the effects of work and industrial therapy on mental health (e.g. Kemp \& Mercer, 1983). Trainees' positive views about ACCEPT staff are also notable in view of evidence suggesting that the development and maintenance of a close and supportive relationship between the client and rehabilitation worker is the sine qua non of vocational rehabilitation (Becker \& Drake, 1994).

It is important to note that, while our findings demonstrate the immediate positive impact of ACCEPT in terms of therapeutic outcomes, we were unable to determine within the study period the extent to which these positive effects were maintained for those who left the ACCEPT programme to take up some form of employment or meaningful occupation. The maintenance of positive effects in the small number of people for whom no follow-up information was available is an area of particular concern as these individuals may have been unable to change their employment situation. The same is true for those who were in sheltered work or volunteer positions as there is a possibility that these kinds of employment substitutes may, for some people, have negative longterm effects (e.g. loss of hope or motivation).

Schneider \& Hallam (1996) administered the LQOLP in seven work schemes in England, one of which involved structured vocational training. ACCEPT trainees generally scored higher in major life domains (e.g. physical health and leisure) than those in the English vocational rehabilitation scheme $(n=16)$. However, scores on overall affect (ABS) and satisfaction with life as a whole were slightly lower for the local group while the overall self-esteem scores of both cohorts were almost identical. It is difficult to explain these differences in view of variations in the economic, social and cultural contexts in which both studies were conducted. The improvement in ACCEPT trainees' attitudes toward their religious practices and beliefs is particularly interesting and may reflect, in part, a greater feeling of hope. Hope has previously been described as a central com- 
ponent of psycho-social rehabilitation (Anthony et al., 1990). However, although people had benefited from their contact with ACCEPT, many were less than satisfied in a number of respects with the quality of their lives generally (although they fared much better than those assessed by Schneider \& Hallam). It is also important to note that LQOLP scores tend to correlate quite highly with depressed mood and, therefore, that changes in these scores may be explained by resolution of depressive symptomatology among trainees. This underline the difficulties in measuring the 'softer' but no less important outcomes of any vocational rehabilitation program owing to the inability to control for factors such as mental and physical health, housing, finances and the local labour market, all of which are likely to impinge on overall wellbeing and quality of life.

\section{Implications for research and practice}

Our findings have important implications for the development and evaluation of any new model of vocational rehabilitation for people with psychiatric disorders. First of all, there is a need to measure and value therapeutic outcomes rather than focusing solely - as is typical of most work in this area - on factors such as job acquisition and earnings. It is also important to recognise that a work placement or volunteer position may represent a significant milestone in the process of obtaining meaningful employment or may constitute an end in itself particularly for the longer-term mentally ill (Kaufman, 1995). This raises further questions in the continuing debate about the use of appropriate outcome measures in judging the success of vocational training activities.

There is an additional need to encourage partnership and communication within and between relevant agencies while at the same time promoting a sense of collective owner- ship and responsibility among all those with a 'stake' in the service. The active support of mental health professionals - as the gatekeepers to vocational training services - is critical to the success of these innovative programmes. In addition, vocational training services ought to be flexible and tailored to client needs, abilities and expectations particularly in view of the current policy emphasis on user choice and participation in service planning. Some aspects of the ACCEPT 'short-sharp' train-and-place model might need to be altered or developed in the future in line with clients' abilities and expressed requirements always mindful of the need to provide appropriate career development and the kinds of interesting and fulfilling job placements which are most likely to lead to long-term success. The need for more diverse provision may also have significant resource implications (e.g. extra training or the more creative use and development of existing resources) and care should be taken that the kind of target-setting commonly associated with European and other types of funding does not present incentives to screen for candidates of high ability, or to support people in low-grade work. Mental health professionals should also give more consideration to ways in which 'at-risk' groups such as mentally disordered offenders and homeless people with mental health needs might be encouraged to participate in vocational training.

\section{Conclusion}

Arguably the ultimate measure of success of any vocational training programme is the extent to which it can find employment for its trainees. However, the results reported here suggest that while the ACCEPT model of vocational training aims, in the first instance, to improve occupational functioning and 
skills, there are additional benefits for clients which may promote recovery from illness and/or prevent relapse. These types of training activities may, therefore, form an essential part of a client's overall package of care provided that the primary symptoms are kept under control.

The triangulation in this study of different types of data, different informants and varying time points converge to indicate that the ACCEPT service is beneficial, at least in the short-term, for a certain group of people with mental health problems. However, it is early days and it remains to be seen to what extent ACCEPT services throughout Europe can adapt to the challenges presented by the many changes in vocational rehabilitation/training for psychiatric populations. Undoubtedly, the success of this new service relies, in part, on the ability and enthusiasm of both clients and staff and the sustaining influence, in the long term, of a network of support services such as social firms and other community initiatives. However, it is unlikely to grow and develop without the vigorous support primarily of clinicians and other mental health professionals, but also employers, and voluntary and statutory agencies and organisations. Further research on ACCEPT and other models and schemes of vocational rehabilitation/training for the mentally ill in the UK and elsewhere in Europe is required to address the many questions and concerns remaining in this area (e.g. clients' longerterm adjustment, the identification and follow-up of 'leavers' and factors predictive of success).

\section{Acknowledgements}

We would like to thank ACCEPT for funding this study and their staff and clients for their co-operation and participation in the research.

\section{References}

Anthony, W.A. \& Jansen, M.A. (1984). Predicting the vocational capacity of the chronically ill. American Psychologist, 39, 537-544.

Anthony, W.A. \& Liberman, R.P. (1986). The practice of psychiatric rehabilitation: Historical, conceptual and research base. SchizophreniaBulletin, 12, 542-559.

Anthony, W.A., Cohen, M. \& Farkas, M. (1990). Psychiatric Rehabilitation. Boston: Centre for Psychiatric Rehabilitation.

Arns, P.G. \& Linney, J.A. (1993). Work, self and life satisfaction for persons with severe and persistent mental disorders. PsychosocialRehabilitationJournal, 17, 63-79.

Bachrach, L. (1992). Psychosocial rehabilitation and psychiatryin the care of long-term patients. American Journal of Psychiatry, 149, 1455-1463.

Becker, D. R. \& Drake, R.E. (1994). Individual placement and support: a community mental health centre approach to vocational rehabilitation. Community Mental Health Journal, 30, 193-206.

Bennett, D .H. (1983). The historical development of rehabilitation services. In F.N. Watts \& D.H. Bennett(Eds.), Theory and Practice of Psychiatric Rehabilitation. Chichester: John Wiley \& Sons.

Bond, G.R. \& Boyer, S.L. (1988). Rehabilitation programs and outcomes. In J.A. Ciardiello \& M.D. Bell (Eds.), Vocational Rehabilitation of Persons with Prolonged Mental Illness. Baltimore: Johns Hopkins University.

Bond, G., Drake, R.E., Mueser, K.T. \& Becker, D.R. (1997). An update on supported employment for people with severe mental illness. Psychiatric Services, 48, 335-346.

Bradburn, N. (1969). The Structure of Psychological Well-being. Chicago: Aldine.

Dick, N. \& Shepherd, G. (1994). Work and mental health: a preliminary test of Warr's model in sheltered workshops for the mentally ill. Journal of Mental Health, 3, 387-400.

Drake, R.E., Becker, D.R., Biesanz, J.C., Torrey, W. C., McHugo, G.J. \& Wyzik, P.F. (1994). Rehabilitative day treatment v. supported employment: I. Vocational outcomes. Community Mental Health Journal, 30, 519-532.

Ekdawi, M.Y. \& Conning, A.M. (1994). Psychiatric Rehabilitation. A practical guide. London: Chapman and Hall.

Ewing, J.A. \& Rouse, B.A. (1970). Identifying the hidden alcoholic. Presented at the 29th InternationalCongresson Alcohol and Drug Dependence, Sydney, Australia, 3 February. 
Goldberg, D.P. (1978). Manual of the General Health Questionnaire. Windsor: NFER-Nelson.

Grove, B. (1999). Mental health and employment: Shaping a new agenda. Journal of Mental Health, 8, 131-140.

Jahoda, M. (1981). Work, employment and unemployment: values, theories and approaches in social research. American Psychologist, 36, 184-191.

Kaufman, C. (1995). The self-helpemploymentcentre: some outcomes from the first year. Psychosocial Rehabilitation Journal, 18, 145-162.

Kemp, N.J. \& Mercer, A. (1983). Unemployment, disability and rehabilitation centres and their effects on mental health. Journal of Occupational Psychology, 56, 37-48.

Kiresuk, T. \& Sherman, R. (1968). Goal attainment scaling: A general method of evaluating comprehensive mental health programs. Community Mental Health Journal, 1, 4.

Lam, D.H. \& Power, M.J. (1991). A questionnaire designed to assess roles and goals: A preliminary study. British Journal of Medical Psychology, 64, 359-373.

Lehman, A. (1995). Vocationalrehabilitationin schizophrenia. Schizophrenia Bulletin, 21, 645-656.

McCrohan, N., Mowbray, C.T., Bybee, D. \& Harris, S. (1994). Employment histories and expectations of people with psychiatric disorders. Rehabilitation Counselling Bulletin, 38, 59-71.

McCrum, B., Burnside, L. \& Duffy, T.L. (1997). Organising for work: A job clinic for people with mental health needs. Journal of Mental Health, 6 , 503-513.

Oliver, J., Huxley, P. \& Bridges, P. (1995). Quality of life andmentalhealth services. London: Routledge.

Pilling, S. (1991).Rehabilitationand Community Care, London: Routledge.
Pozner, A., Ling Ng, M., Hammond, J. \& Shepherd, G. (1996) Working it Out. London: Sainsbury Centre for Mental Health.

Rosenberg, M. (1965). Societyand the AdolescentSelfimage. Princeton: Princeton University Press.

Schneider, J. \& Hallam, A. (1996). Specialist work schemes and mental health. Discussion paper 1178. Canterbury: University of Kent at Canterbury (PSSRU).

Schneider, J. (1998). Work interventions in mental health care: some arguments and recent evidence. Journal of Mental Health, 7, 81-94.

Shepherd, G. (1997) Vocational rehabilitation in psychiatry: an historical perspective(Foreword) In B. Grove, M. Freudenberg, A. Harding \& D. O' Flynn The Social Firm Handbook: New directions in the employment, rehabilitationand integration of people with mental health problems. Brighton: Pavilion Publishing.

Velasquez, J.A. \& McCubbin, H.I. (1980). Towards establishing the effectiveness of establishing community-basedresidentialtreatment:programevaluation by experimental research. Journal of Social Service Research, 3, 337-359.

Wainwright, T., Holloway, F. \& Brugha, T. (1988). Day care in an inner city. In A. Lavender \& F. Holloway (Eds.), Community Care in Practice: Servicesfor the continuing care client. Chichester: John Wiley \& Sons.

Warr, P. (1984). Job loss, unemployment and psychological well-being. In V.L. Allen \& E. ven der Vliert(Eds.), Role Transitions. New York: Plenum Publications.

Wing, J.K. (1981) Recent advances in understanding schizophrenia In J.K.Wing, P.Kielohlz \& W.M. Zinn (Eds.) Rehabilitationof Patients with Schizophrenia and Depression. Bern: Hans Stubler. 